\title{
Managing patients with multimorbidity: systematic review of interventions in primary care and community settings
}

\author{
(c) $(1)$ (8) OPEN ACCESS
}

\author{
Susan M Smith associate professor of general practice ${ }^{1}$, Hassan Soubhi adjunct professor of family \\ medicine $^{2}$, Martin Fortin professor of family medicine ${ }^{2}$, Catherine Hudon associate professor of \\ family medicine ${ }^{2}$, Tom O'Dowd professor of general practice ${ }^{3}$
}

'Department of General Practice, Royal College of Surgeons, Dublin 2, Ireland; ${ }^{2}$ Department of Family Medicine, University of Sherbrooke, Chicoutimi, QC, Canada; ${ }^{3}$ Department of Public Health and Primary Care, Trinity College Centre for Health Sciences, Dublin 24, Ireland

\begin{abstract}
Objective To determine the effectiveness of interventions designed to improve outcomes in patients with multimorbidity in primary care and community settings.

Design Systematic review.

Data sources Medline, Embase, CINAHL, CAB Health, Cochrane centra register of controlled trials, the database of abstracts of reviews of effectiveness, and the Cochrane EPOC (effective practice and organisation of care) register (searches updated in April 2011).

Eligibility criteria Randomised controlled trials, controlled clinical trials, controlled before and after studies, and interrupted time series analyses reporting on interventions to improve outcomes for people with multimorbidity in primary care and community settings. Multimorbidity was defined as two or more chronic conditions in the same individual. Outcomes included any validated measure of physical or mental health and psychosocial status, including quality of life outcomes, wellbeing, and measures of disability or functional status. Also included were measures of patient and provider behaviour, including drug adherence, utilisation of health services, acceptability of services, and costs.

Data selection Two reviewers independently assessed studies for eligibility, extracted data, and assessed study quality. As meta-analysis of results was not possible owing to heterogeneity in participants and interventions, a narrative synthesis of the results from the included studies was carried out.

Results 10 studies examining a range of complex interventions totalling 3407 patients with multimorbidity were identified. All were randomised controlled trials with a low risk of bias. Two studies described interventions for patients with specific comorbidities. The remaining eight studies focused on multimorbidity, generally in older patients.
\end{abstract}

Consideration of the impact of socioeconomic deprivation was minimal. All studies involved complex interventions with multiple components. In six of the 10 studies the predominant component was a change to the organisation of care delivery, usually through case management or enhanced multidisciplinary team work. In the remaining four studies, intervention components were predominantly patient oriented. Overall the results were mixed, with a trend towards improved prescribing and drug adherence. The results indicated that it is difficult to improve outcomes in this population but that interventions focusing on particular risk factors in comorbid conditions or functional difficulties in multimorbidity may be more effective. No economic analyses were included, although the improvements in prescribing and risk factor management in some studies could provide potentially important cost savings.

Conclusions Evidence on the care of patients with multimorbidity is limited, despite the prevalence of multimorbidity and its impact on patients and healthcare systems. Interventions to date have had mixed effects, although are likely to be more effective if targeted at risk factors or specific functional difficulties. A need exists to clearly identify patients with multimorbidity and to develop cost effective and specifically targeted interventions that can improve health outcomes.

\section{Introduction}

Healthcare systems are placing increasing emphasis on the management of chronic diseases. Despite the increasing numbers of patients with two or more chronic conditions, or multimorbidity, the delivery of care is usually built around single diseases. ${ }^{1}$ A well established evidence base highlights the impact and costs associated with multimorbidity in both younger and older patients. ${ }^{2-6}$ Patients with multimorbidity are more likely 
to die prematurely than those with single conditions, be admitted to hospital, and have longer hospital stays. ${ }^{67}$ They have poorer quality of life, have loss of physical functioning, and are more likely to experience depression and to be receiving multiple drugs with consequent difficulties with adherence. ${ }^{8}{ }^{9}$ Evidence of the impact of socioeconomic deprivation is also clear as onset of multimorbidity occurs 10-15 years earlier in people living in the most deprived areas compared with those living in the least deprived areas. ${ }^{10}$

Despite the increasing numbers of patients with multimorbidity, evidence on the effectiveness of interventions to improve outcomes in such patients is limited. The clinical care of these patients is complex and the evidence base for managing chronic conditions is based largely on trials of interventions for single conditions, which too often exclude patients with multimorbidity. ${ }^{112}$ Clinical care is often fragmented, involving both primary care and multiple secondary care specialists who may not be communicating effectively, and there is a clear need for integrated care of multiple conditions. ${ }^{13-16}$

We determined the effectiveness of interventions designed to improve physical, psychosocial, and health service utilisation outcomes in patients with multimorbidity in primary care and community settings.

\section{Methods}

We used the methodology of the Cochrane collaboration. The protocol and full review are available on the Cochrane Library. ${ }^{17}$

\section{Inclusion criteria}

The types of studies we considered eligible were randomised controlled trials, controlled clinical trials, controlled before and after studies, and interrupted time series analyses (meeting the quality criteria of the Cochrane Effective Practice And

Organisation of Care Review Group). Studies published in all languages were eligible for inclusion.

Participants included people or populations with multimorbidity. We adopted the most widely used definition of multimorbidity - that is, the coexistence of multiple chronic diseases and medical conditions in the same individual (usually defined as two or more conditions). ${ }^{218}$ We used the World Health Organization definition of chronic disease, which is "health problems that require ongoing management over a period of years or decades. ${ }^{19}$ We included studies that only specifically identified participants or subgroups of participants as having multimorbidity.

We included any type of intervention that was specifically directed towards a group of patients defined as having multimorbidity. Interventions based only in primary care or community settings were included and we adopted the definition of primary healthcare as providing "integrated, easy to access, health care services by clinicians who are accountable for addressing a large majority of personal health care needs, developing a sustained and continuous relationship with patients, and practicing in the context of family and community." ${ }^{20} \mathrm{We}$ included care delivered in community settings by practitioners fulfilling the basic criteria for primary care-that is, they are available to treat all common conditions in all age groups and have an ongoing relationship with their patients.

To group interventions for this review we used the taxonomy of interventions developed by the Cochrane Effective Practice And Organisation of Care Review Group (box).

Where interventions had multiple components we defined each using the taxonomy and highlighted the predominant one of the intervention for each study. We excluded professional educational interventions or research initiatives where there was no specified structured clinical care delivered to an identified group of patients with multimorbidity and interventions targeted at comorbid conditions where the intervention was targeted solely at one of the conditions.

\section{Outcome measures}

We included validated outcome measures reporting on physical health; patient reported measures reflecting psychological and functional status, including wellbeing, quality of life, and disability or pain; utilisation of health services, including hospital admissions and visits to doctors; patient behaviour, including diet and exercise and measures of drug adherence; and provider behaviour, including prescribing. We also included any available economic outcomes reported in included studies.

\section{Search strategy}

The search strategy was particularly challenging as multimorbidity is a relatively new term and is sometimes used synonymously with the term comorbidity, although this tends to be used in relation to diseases that coexist with an index condition. Comorbidity is a MeSH term, whereas multimorbidity is not, so we included both terms in our search. For pragmatic reasons and because multimorbidity is a relatively new concept we limited the Medline search to articles indexed from 1990 onwards.

We searched the following electronic databases: Medline, Embase, CINAHL, CAB Health, the Cochrane central register of controlled trials (CENTRAL), the database of abstracts of reviews of effectiveness, AMED-Allied and Complimentary Medicine (1985 to current), and the Cochrane EPOC (effective practice and organisation of care) register (searches updated in April 2011). We also searched reference lists of all included papers and contacted the authors of relevant papers for any further published or unpublished work (see the supplementary file for the full Medline search strategy).

\section{Data extraction}

Potentially relevant studies were determined by review of the abstracts of search results. We retrieved the full text copies of all articles identified as potentially relevant. Two authors (SS and HS) independently assessed each of these 30 retrieved articles for inclusion, extracted data, and cross checked data abstraction forms using a modified version of the Cochrane Effective Practice And Organisation of Care data collection checklist. The review authors resolved disagreements about eligibility and quality by consensus.

\section{Assessment of risk of bias}

Two authors (SS and HS) independently assessed risk of bias using standard Cochrane criteria, including sequence generation, allocation concealment, blinding, protection against contamination, reliability of primary outcomes, follow up of patients, and performance of baseline measurement.

\section{Data analysis}

For each trial we calculated results in terms of absolute difference (mean or proportion of outcome in intervention group minus control at study completion) and relative percentage difference (absolute difference divided by post-intervention score in the control group). We contacted authors for missing data. If studies were identified that were similar in terms of 


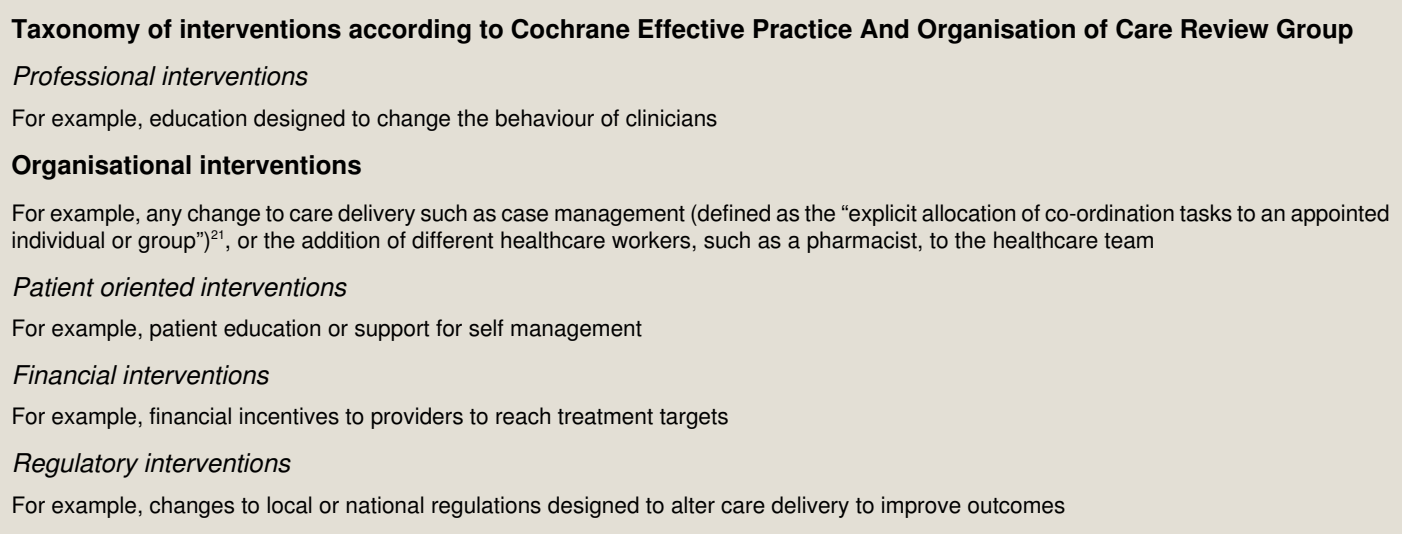

settings, patients, interventions, outcome assessment, and study methods we planned to carry out meta-analysis. This was not, however, possible owing to noticeable clinical heterogeneity. We therefore carried out a narrative synthesis of the results from the included studies.

\section{Results}

Figure $1 \Downarrow$ outlines the search. Overall, 20177 potentially eligible titles were identified.

Overall, 17 of 30 full text articles screened for eligibility were excluded on the basis of study design and intervention type. Three ongoing studies led to the identification of 10 studies included in the narrative synthesis. All 10 were randomised controlled trials, totalling 3407 patients (table $1 \Downarrow$ ) The studies varied in duration from eight weeks to two years, with most lasting 6-12 months. Eight of the 10 studies included patients with a broad range of conditions, ${ }^{22-29}$ whereas the remaining two focused on comorbidities: coexisting depression and hypertension $^{30}$ and coexisting depression and diabetes or heart disease.$^{31}$ Most were based in the United States, apart from one study set in the United Kingdom ${ }^{27}$ and one in Canada. ${ }^{26}$ All were funded by a government or university grant or charitable foundation.

In most of the included studies the comparator was usual medical care, which was supplemented by a newsletter or leaflet ${ }^{23}{ }^{24}$ or assessment but no follow-on intervention. ${ }^{27}{ }^{30} 31$ One study used an attention control based on an unrelated topic, with control patients also attending a group session. ${ }^{25}$ No study specifically reported patient or family involvement in the intervention design. Whereas only two of the six organisational studies were based on explicit theoretical frameworks, all four of the patient oriented interventions were guided by a variety of frameworks (table 1). In the four organisational studies that did not specify a theoretical framework, the intervention was presented as enhancing multidisciplinary teamwork. Only one of the 10 studies specifically targeted disadvantaged patients or those on low incomes. ${ }^{23}$ Socioeconomic status was recorded at baseline in three of the remaining studies, but no study considered a differential effect of the intervention based on socioeconomic status of participants.

\section{Description of interventions}

The interventions were all multifaceted (table 1). Although the interventions identified all multiple components they could be divided into two main groups: predominantly organisational $^{22} 2627$ 29-31 and predominantly patient oriented. ${ }^{23-2528}$ No study involved financial incentives or regulatory interventions. Table $2 \Downarrow$ outlines the elements of the interventions in the included studies.

\section{Risk of bias in included studies}

Overall the studies had low risk of bias (fig $2 \Downarrow$ ). Baseline measurement, use of reliable outcomes, and follow-up of participants was done in most studies. Randomisation, allocation concealment, and blinding of outcome assessment was less reliably reported or carried out. Only two of the 10 studies had a cluster design ensuring no contamination of control patients. $^{22} 29$ The patient oriented interventions were less likely to result in contamination of control patients as the intervention was not delivered through healthcare providers. The two cluster randomised controlled trials had accounted for design effects in their analysis, with no unit of analysis errors. ${ }^{22} 29$

\section{Effects by type of intervention}

As interventions could be classified generally as organisational or patient oriented, results are presented in these groupings. It must be stressed that all interventions were complex and multifaceted, with overlapping components across these two classifications. No study attempted to link outcomes to specific intervention components.

Six studies had organisational interventions. ${ }^{22} 2627$ 29-31 These predominantly involved case management and coordination of care or the enhancement of skill mix in multidisciplinary teams. Overall the results indicated that organisational interventions targeted at specific risk factor management or that focused on areas where patients have difficulties, such as with the management of medicines, were more likely to be effective. Organisational interventions with a broader focus, such as case management or changes in delivery of care, seemed less effective.

Four studies had predominantly patient oriented interventions. ${ }^{23-25} 28$ All aimed to deal with patient health related behaviour and did not engage or intervene with healthcare providers directly. In general, patient oriented interventions not linked to healthcare delivery seemed less effective, although the exception was a professional led patient oriented intervention focused on functional difficulties, which was associated with significant improvements including a reduction in mortality in the intervention group. ${ }^{24} 32$

\section{Physical health outcomes}

Four of the six studies with organisational interventions reported physical health outcomes. Two of these reported statistically significant improvements in blood pressure. ${ }^{30}{ }^{31}$ One also reported statistically significant improvements in glycated 
haemoglobin and low density lipoprotein cholesterol levels and in their composite primary outcome, which included these three physical health outcomes and a depression score. ${ }^{31}$

Two studies with patient oriented interventions reported physical health outcomes. One of these reported mixed results for three outcomes, with significant improvements in dietary behaviour and support for healthy lifestyle but no improvement in physical activity. ${ }^{23}$ The other reported a follow-up study, which found significantly reduced mortality in the first two years after a focused occupational therapy and physiotherapy led intervention targeting functional difficulty and fall prevention (table 1)

\section{Mental health outcomes}

Three organisational studies presented data on mental health outcomes. $^{29-31}$ Two of these showed significant improvements in depression related outcomes. ${ }^{30} 31$ One of the four patient oriented studies presented data on mental health outcomes and found no difference in the management of cognitive symptoms between groups at study completion. ${ }^{28}$

\section{Patient reported functional health outcomes}

Four organisational type studies involved patient reported functional health outcomes. ${ }^{26} 272931$ One found significant improvements, ${ }^{31}$ whereas another found significant improvements in social activities but no significant differences in scores on the short form 36 health survey (SF-36) or health assessment questionnaire. ${ }^{29}$ All four of the patient oriented studies reported a range of these outcomes (table 1) but only one reported improvements, which occurred in two of the six psychosocial outcomes reported. ${ }^{24}$

\section{Utilisation of health services}

Five of the six organisational studies reported outcomes on utilisation of health services. ${ }^{22} 26272931$ Only one of these reported significant improvements across a variety of measures related to hospital admissions, although numbers of admissions were small in most studies. Three studies reported on visits to a range of health service providers and none showed significant changes in health service use. ${ }^{22} 2629$ One of the four patient oriented studies reported outcomes on health services utilisation and found significant improvements across a variety of measures related to hospital admissions. ${ }^{28}$

\section{Patient behaviour}

Only one organisational study reported measures relating to drug use and adherence and found significant improvements in proportions of intervention patients adhering to both antidepressants and antihypertensives, as measured using automated counting systems in the caps of medicine bottles (MEMS caps). ${ }^{30}$ Two organisational studies provided data on a variety of outcomes related to health behaviours by patients and found no significant improvement. ${ }^{29}{ }^{31}$ Two patient oriented studies also reported on patient health behaviours, ${ }^{23}{ }^{28}$ although only one reported significant improvements in diet behaviour scores and in minutes of walking per week. ${ }^{23}$

\section{Provider behaviour}

Two organisational studies reported measures relating to prescribing by practitioners or the management of medicines, both of which indicated significant benefits for intervention patients. One study reported drug adjustments for five classes of drugs related to the comorbid conditions being studied and found statistically significant differences for four of these five groups. ${ }^{31}$ The other study reported a significant reduction in pharmaceutical care issues in intervention patients, which would have resulted from changes in both intervention by pharmacists and prescribing by general practitioners. ${ }^{27}$

Two other organisational studies reported on the behaviours of providers related to the management of chronic disease or preventive care. ${ }^{22}{ }^{26}$ The guided care study included a secondary outcome of a validated patient measure called the patient assessment of chronic illness care (PACIC) score. ${ }^{22}$ The aggregate quality score was significantly improved. The other study reported measures relating to chronic disease management and preventive care based on data from charts. ${ }^{26}$ Both outcomes were significantly improved in the intervention group (table 1).

\section{Acceptability of services}

Only two organisational studies reported satisfaction with treatment as secondary outcomes. One study reported that significantly more intervention patients were satisfied with their care at study completion compared with those experiencing usual care. ${ }^{31}$ The other study reported on the changes in satisfaction for providers as part of an overall examination of the effect of the intervention on providers. ${ }^{22}$ Five of the 11 domains relating to satisfaction with service provision did not improve significantly. ${ }^{22}$

\section{Costs}

Four organisational studies provided data on costs..$^{22} 2931$ These data were difficult to compare across the studies and were often presented in relation to non-significant results, indicating that no study had identified a significantly cost effective intervention.

Two patient oriented studies provided data on direct costs of providing the intervention. ${ }^{24}{ }^{28}$ One calculated that the reduction in hospital admissions led to a saving in healthcare costs per participant of $\$ 750$ ( $£ 478$; $€ 611$ ), which was 10 times the cost of the intervention.

\section{Comorbidity versus multimorbidity studies}

Two of the 10 included studies focused on comorbidity rather than on multimorbidity in general. ${ }^{30}$ Both of these studies had organisational type interventions and were able to use more disease focused interventions and outcome measures. Both showed more significant intervention effects than the multimorbidity studies.

\section{Discussion}

Multimorbidity presents an important clinical and organisational challenge to the current single system approach to the management of chronic disease. In this review we identified 10 relatively recent randomised trials (up to April 2011). Even within this small number of studies the variation in participants and interventions was substantial and a variety of theoretical frameworks was applied. In two studies the focus was on comorbid conditions, whereby the interventions were directed at prespecified conditions. In the other studies, which included patients with any combination of conditions, the focus tended to be on older patients and the interventions had multiple components, making comparison between studies and between intervention components difficult. Overall these studies suggest that organisational interventions targeted at the management of specific risk factors or focused on areas where patients have difficulties, such as with functional ability or the management of medicines, seem more likely to be effective. Organisational interventions that have a broader focus, such as case 
management or changes in delivery of care, seem less effective. The patient oriented interventions that were not linked to healthcare delivery or specific functional difficulties were also less effective.

In general the results were mixed and inconclusive, particularly those relating to physical health outcomes. The lack of focus on physical health measures may reflect the challenge in research on multimorbidity, as disease specific clinical outcomes cannot be used. Three studies measured outcomes relating to prescribing, use of drugs, and drug adherence and all found significant benefits. The studies, however, may be too short for these benefits to translate into improvements in physical health outcomes. Costs were presented in six studies but data were only provided on direct costs. The results relating to improved prescribing and risk factor management, particularly in the comorbidity trials, indicate a potential for these interventions to reduce health service costs over longer periods.

Unsurprisingly most of the studies in this review were relatively recent, as research on multimorbidity is a conceptually new area and to date has focused on description and impact rather than on interventions. Earlier studies tended to focus on comorbidity rather than multimorbidity. The improvements found in studies with a focus on comorbid conditions are likely to be related to the strong focus in these interventions of targeting specific conditions. Although it is more challenging to design interventions for people with a broad range of conditions, interventions that seemed more effective in this group were those that targeted specific areas of concern for patients. One of the more recent included studies was a large well designed and executed randomised trial of a broad organisational intervention, the "guided care" model, targeted at high risk people with multimorbidity, but which found no significant benefit overall. ${ }^{22}$ However, a preplanned subgroup analysis within this trial indicated significant improvements in the use of some health services in the patients enrolled in one of the participating care plans (Kaiser-Permanente, $n=365,43 \%$ of full sample). This difference highlights the importance of the healthcare delivery setting into which new interventions are added. Indeed, some of the patient oriented interventions were delivered independently of patients' healthcare, and most of these studies had limited effectiveness, suggesting that interventions should be integrated into the healthcare system. The results of the patient oriented intervention studies were consistent with those of the Cochrane review on lay led self management support programmes, which found no evidence that these interventions improve psychological health, symptoms, or health related quality of life, or that they significantly alter healthcare use. ${ }^{33}$

\section{Strengths and weaknesses of this review}

To our knowledge this is the first systematic review of interventions for patients with multimorbidity. Potential limitations in the search process related to the lack of a MeSH term for multimorbidity. We therefore used broad search terms, which led to a high yield of citations to be searched and a need to limit the Medline search to 1990 onwards. The review authors are, however, active researchers in the discipline of multimorbidity and we are unaware of any potentially eligible studies missed by the search. We were also unable to retrieve missing data from some authors. As no meta-analysis was undertaken this did not lead to any appreciable bias. We were unable to group sufficient numbers of studies with similar interventions to comment on which elements of interventions (for example, the use of community pharmacists) seemed most effective and to compare our review to other reviews of these interventions.

\section{Implications for clinical practice and future research}

Multimorbidity is common in clinical practice, and evidence supporting specific interventions is limited. Most of the studies in this review focused on older patients; however, it is also important to deal with the needs of younger patients with multimorbidity, which are likely to be different and to include problems related to employment and absenteeism. ${ }^{34}$ Absolute numbers of patients with multimorbidity are higher in those aged less than 65 years, ${ }^{10}$ and a recent systematic review on prevalence studies on multimorbidity reported a low prevalence before age 40 followed by a steep increase and a plateau after age 70 . This would suggest that interventions should target patients across the age spectrum. ${ }^{35}$ There was minimal consideration of the impact of socioeconomic deprivation in the included studies, and no study considered the possibility of a differential effect of interventions in different socioeconomic groups. Research in Scotland has found that people in the poorest socioeconomic groups are more likely to develop multimorbidity at a younger age and to have greater mental health problems compounding difficulties in their management. ${ }^{10}$

Research on multimorbidity would be facilitated by the inclusion of multimorbidity as a MeSH term. Otherwise, related literature searches are particularly complex and time consuming. An additional challenge for researchers is to define a set of generic outcome measures that incorporate physical functioning and quality of life and that are responsive to change over time. The recent work of PROMIS (patient reported outcomes measurement information system) provides validated and useful patient reported outcomes that will be particularly relevant for those researching interventions to improve outcomes for patients with multimorbidity. ${ }^{36}$

Future research should be planned in collaboration with policy makers to ensure applicability and successful integration of interventions into current delivery systems. Studies must include clear conceptual definitions of multimorbidity and the differentiation of multimorbidity from other related concepts such as comorbidity, complexity, frailty, and vulnerability. Without these definitions and consideration of related theoretical concepts, the generalisability or applicability of studies for patients with multimorbidity (with a broader definition than only two or three diseases) will be uncertain, as is the case for many of the studies in this review, particularly those with a specific focus on comorbidity.

The review has highlighted the lack of a clear theoretical framework guiding interventions for multimorbidity at present. There is still a need for prospective cohort studies that will give more information on the trajectory of patients with multimorbidity across all ages and socioeconomic groups. ${ }^{37}$ Researchers in this area need to collaborate and develop consensus on which models are likely to be most appropriate for multimorbidity. Once identified, authors who develop interventions should consider the individual components of the interventions and the evidence base behind each and link these to relevant outcomes, including health economic analyses.

\section{Conclusion}

This review highlights the paucity of research into interventions to improve outcomes for patients with multimorbidity, with the focus to date being on comorbid conditions or multimorbidity in older patients. The review indicates that interventions targeted 
either at specific combinations of common conditions or at specific problems for patients with multiple conditions, may be more effective. Further research is, however, needed and future interventions should be developed in ways that allow rigorous evaluations that will add to the evidence. There is a need for clear and broader definitions of participants, consideration of appropriate outcomes, and further pragmatic studies based in primary care settings.

We thank Alain Mayhew, Sasha Shepperd, Merrick Zwarenstein, Jeremy Grimshaw, Doug Salzwedel, and Michelle Fiander of the Cochrane EPOC review group; Ailbhe Mealy who provided administrative support during the initial drafting of the review; Sophie Hill, Craig Ramsay, Sarah Dennis, Luciana Ballini, and Martin Eccles for their suggestions and comments during the Cochrane review process; Chris Salisbury, Stewart Mercer and Frances Mair during the BMJ review process; and Emma Wallace who provided additional comments and feedback.

Contributors: SMS conceived, coordinated, and designed the review. HS helped coordinate the review, assessed studies for inclusion, and extracted data from included studies. MF, CH, and TO'D, along with SMS and HS, contributed to all stages of the protocol and review and were involved in writing all review drafts and responding to peer review comments.

Funding: This review was not directly funded by any external organisation. SMS and TO'D are affliliated to the HRB Centre for Primary Care Research, which is funded by the Health Research Board of Ireland (http://www.hrbcentreprimarycare.ie/).

Competing interests: All authors have completed the ICMJE uniform disclosure form at www.icmje.org/coi_disclosure.pdf (available on request from the corresponding author) and declare: no support from any organisation for the submitted work; no financial relationships with any organisations that might have an interest in the submitted work in the previous three years; and no other relationships or activities that could appear to have influenced the submitted work.

Ethical approval: Not required.

Data sharing: No additional data available.

1 Fortin M, Bravo G, Hudon C, Vanasse A, Lapointe L. Prevalence of multimorbidity among adults seen in family practice. Ann Fam Med 2005;3:223-8.

2 Fortin M, Soubhi H, Hudon C, Bayliss EA, van den Akker M. Multimorbidity's many challenges. BMJ 2007;334:1016-7.

3 Marengoni A, Angleman S, Melis R, Mangialasche F, Karp A, Garmen A, et al. Aging with multimorbidity: a systematic review of the literature. Ageing Res Rev 2011;10:430-9.

4 Smith SM, O'Dowd T. Chronic diseases: what happens when they come in multiples? $\mathrm{Br}$ J Gen Pract 2007;57:268-70.

5 Taylor AW, Price K, Gill TK, Adams R, Pilkington R, Carrangis N, et al. Multimorbidity-not just an older person's issue. Results from an Australian biomedical study. BMC Public Health 2010;10:718.

6 Vogeli C, Shields AE, Lee TA, Gibson TB, Marder WD, Weiss KB, et al. Multiple chronic conditions: prevalence, health consequences, and implications for quality, care management, and costs. J Gen Intern Med 2007;22(suppl 3):391-5.

7 Menotti A, Mulder I, Nissinen A, Giampaoli S, Feskens EJ, Kromhout D. Prevalence of morbidity and multimorbidity in elderly male populations and their impact on 10-year all-cause mortality: the FINE study (Finland, Italy, Netherlands, Elderly). J Clin Epidemiol 2001;54:680-6.

8 Fortin M, Lapointe L, Hudon C, Vanasse A, Ntetu AL, Maltais D. Multimorbidity and quality of life in primary care: a systematic review. Health Qual Life Outcomes 2004;2:51.

9 Townsend A, Hunt K, Wyke S. Managing multiple morbidity in mid-life: a qualitative study of attitudes to drug use. BMJ 2003;327:837.
10 Barnett K, Mercer SW, Norbury M, Watt G, Wyke S, Guthrie B. The epidemiology of multimorbidity in a large cross-sectional dataset: implications for health care, research and medical education. Lancet 2012: published online 9 May.

11 Fortin M, Dionne J, Pinho G, Gignac J, Almirall J, Lapointe L. Randomized clinical trials: do they have external validity for patients with multiple comorbidities? Ann Fam Med 2006;4:104-8.

12 Starfield B. New paradigms for quality in primary care. Br J Gen Pract 2001;51:303-9.

13 Bayliss EA. Simplifying care for complex patients. Ann Fam Med 2012;10:3-5.

14 Kamerow D. How can we treat multiple chronic conditions? BMJ 2012;344:e1487.

15 Smith SM, O'Kelly S, O'Dowd T. GPs' and pharmacists' experiences of managing multimorbidity: a "Pandora's box." Br J Gen Pract 2010;60:285-94.

16 Stange KC. In this issue: challenges of managing multimorbidity. Ann Fam Med 2012;10:2-3.

17 Smith SM, Soubhi H, Fortin M, Hudon C, O'Dowd T. Interventions for improving outcomes in patients with multimorbidity in primary care and community settings. Cochrane Database Syst Rev 2012;4:CD006560.

18 Van den Akker M, Buntinx F, Metsemakers JF, Roos S, Knottnerus JA. Multimorbidity in general practice: prevalence, incidence, and determinants of co-occurring chronic and recurrent diseases. J Clin Epidemiol 1998;51:367-75.

19 World Health Organization. Innovative care for chronic conditions: building blocks for action. Global report. World Health Organization, 2002.

20 Vanselow N, Donaldson M, Yordy K. A new definition of primary care. JAMA 1995;273:192.

1 Zwarenstein M, Reeves S, Straus S, Pinfold PJG. Case management: effects on professional practice and health care outcomes (protocol). Cochrane Database Syst Rev 2000;4:CD002797.

22 Boult C, Reider L, Leff B, Frick KD, Boyd CM, Wolff JL, et al. The effect of guided care teams on the use of health services: results from a cluster-randomized controlled trial. Arch Intern Med 2011;171:460-6.

23 Eakin E, Bull S, Riley K, Reeves M, McLaghlin M, Gutierrez S. Resources for health: a primary-care-based diet and physical activity intervention targeting urban Latinos with multiple chronic conditions. Health Psychol 2007;26:392-400.

24 Gitlin LN, Winter L, Dennis MP, Corcoran M, Schinfeld S, Hauck WW. A randomized trial of a multicomponent home intervention to reduce functional difficulties in older adults. $J$ Am Geriatr Soc 2006;54:809-16.

25 Hochhalter AK, Song J, Rush J, Sklar L, Stevens A. Making the Most of Your Healthcare intervention for older adults with multiple chronic illnesses. Patient Educ Couns 2010;81:207-13.

26 Hogg W, Lemelin J, Moroz I, Soto E, Russell G. Improving prevention in primary care: evaluating the sustainability of outreach facilitation. Can Fam Physician 2008:54:712-20.

27 Krska J, Cromarty JA, Arris F, Jamieson D, Hansford D, Duffus PR, et al. Pharmacist-led medication review in patients over 65: a randomized, controlled trial in primary care. Age Ageing 2001;30:205-11.

28 Lorig K, Sobel D, Stewart A, Brown B, Bandura A, Ritter P, et al. Evidence suggesting that a chronic disease self-management program can improve health status while reducing hospitalization: a randomised trial. Med Care 1999;37:5-14.

29 Sommers LS, Marton KI, Barbaccia JC, Randolph J. Physician, nurse, and social worker collaboration in primary care for chronically ill seniors. Arch Intern Med 2000;160:1825-33.

30 Bogner HR, de Vries HF. Integration of depression and hypertension treatment: a pilot, randomized controlled trial. Ann Fam Med 2008;6:295-301.

31 Katon WJ, Lin EHB, Von Korff M, Ciechanowski P, Ludman EJ, Young B, et al. Collaborative care for patients with depression and chronic illnesses. N Engl J Med 2010:363:2611-20

32 Gitlin LN, Hauck WW, Dennis MP, Winter L, Hodgson N, Schinfeld S. Long-term effect on mortality of a home intervention that reduces functional difficulties in older adults: results from a randomized trial. JAGS 2009;57:476-81.

33 Foster G, Taylor SJ, Eldridge SE, Ramsay J, Griffiths CJ. Self-management education programmes by lay leaders for people with chronic conditions. Cochrane Database Syst Rev 2007;4:CD005108.

34 Turner BJ, Cuttler L. The complexity of measuring clinical complexity. Ann Intern Med 2011;155:851-2.

35 Fortin M, Stewart M, Poitras M-E, Almirall J, Maddocks H. A systematic review of prevalence studies on multimorbidity: toward a more uniform methodology. Ann Fam Med 2012;10:142-51.

36 PROMIS. Home page. 2012. www. nihpromis.org

37 France EF, Wyke S, Gunn JM, Mair FS, McLean G, Mercer SW. Multimorbidity in primary care: a systematic review of prospective cohort studies. BJGP 2012;62:e297-307.

Accepted: 23 July 2012

\section{Cite this as: BMJ 2012;345:e5205}

This is an open-access article distributed under the terms of the Creative Commons Attribution Non-commercial License, which permits use, distribution, and reproduction in any medium, provided the original work is properly cited, the use is non commercial and is otherwise in compliance with the license. See: http://creativecommons.org/licenses/bync/2.0/ and http://creativecommons.org/licenses/by-nc/2.0/legalcode. 


\section{What is already known on this topic}

Patients with multimorbidity have poorer health outcomes than those with single chronic conditions

Despite the increasing numbers of patients with multimorbidity, the delivery of care is usually built around single diseases

Existing evidence on the effectiveness of interventions to improve outcomes in patients with multimorbidity is limited

\section{What this study adds}

This review identified 10 randomised trials, highlighting the paucity of research into interventions to improve outcomes for patients with multimorbidity

The focus to date has been on comorbid conditions or multimorbidity in older patients

The review indicates that interventions targeted either at specific combinations of common conditions or at specific problems for patients with multiple conditions, may be more effective

\section{Tables}

\section{Table 1| Characteristics of studies included in systematic reviews}

\begin{tabular}{|c|c|c|c|c|c|}
\hline Study & Study participants & $\begin{array}{l}\text { Duration and } \\
\text { follow-up }\end{array}$ & $\begin{array}{l}\text { Intervention elements; } \\
\text { (theoretical framework, where } \\
\text { specified) }\end{array}$ & Outcomes & $\begin{array}{l}\text { Results (primary outcomes, where } \\
\text { specified): intervention versus } \\
\text { control }\end{array}$ \\
\hline $\begin{array}{l}\text { Predominantly } \\
\text { organisational } \\
\text { interventions: }\end{array}$ & & & & & \\
\hline
\end{tabular}

Bognor Aged $>50, \quad$ Intervention six Care manager, structured visits, Depression scores (CES-D CES-D score 9.9 v 19.3 , P=0.006;

$2008^{30} \quad$ depression and weeks, follow-up telephone contact, and patient score); systolic blood pressure; systolic blood pressure (mm Hg) 127.3 hypertension ( $\mathrm{n}=64$ ) two weeks later care plans (adherence based drug adherence $\quad v 141.3, \mathrm{P}=0.003 ; \geq 80 \%$ adherence to model) antidepressants $23 \% \vee 10 \%, P=0.001$, $\geq 80 \%$ adherence to antihypertensives $25 \%$ v $10 \%, \mathrm{P}<0.001$

Boult $2011^{22}$ Aged $>65$, multiple Intervention 18 Organisational: guided care $\quad$ Primary outcome: health Adjusted intervention:control ratio of conditions and high months, follow-up nurse managers, enhanced service use hospital service use: hospital 30 day service use $(n=904)$ at six and 18 multidisciplinary team, home admissions, nursing facility use, readmissions 1.01 (95\% $\mathrm{Cl} 0.83$ to assessments and monthly visits, and home healthcare 1.23); hospital days 0.79 (0.53 to 1.16); monitoring, patient care plans. $\quad$ episodes. Secondary outcomes: skilled nursing facility admissions 1.00 Professional: education of nurse quality of chronic care (PACIC) $(0.77$ to 1.30$)$; skilled nursing facilities managers. Patient: self scores days $0.92(0.6$ to 1.4$)$; emergency management support department visits 0.84 (0.48 to 1.47$)$; primary care visits 1.04 (0.81 to 1.34 ); speciality care visits 1.02 (0.91 to 1.14$)$ home healthcare episodes $1.07(0.93$ to 1.23 ); (PACIC) scores 0.70 ( 0.53 to 0.93 )

\begin{tabular}{|c|c|c|c|c|c|}
\hline Hogg $2008^{26}$ & $\begin{array}{l}\text { Aged }>50 \text {, at least } \\
\text { two conditions and } \\
\text { at risk of } \\
\text { experiencing } \\
\text { adverse outcome } \\
(n=241)\end{array}$ & $\begin{array}{l}\text { Intervention } 15 \\
\text { months, follow-up } \\
\text { on completion of } \\
\text { intervention }\end{array}$ & $\begin{array}{l}\text { Enhanced multidisciplinary team } \\
\text { with structured home visit, drug } \\
\text { review, and patient care plans }\end{array}$ & $\begin{array}{l}\text { Primary outcome: chronic } \\
\text { disease management score. } \\
\text { Secondary outcomes included } \\
\text { preventive care delivery score, } \\
\text { physical health outcomes, } \\
\text { health service use, } \\
\text { psychosocial measures, quality } \\
\text { of life, and activities of daily } \\
\text { living }\end{array}$ & $\begin{array}{l}\text { Difference in chronic disease } \\
\text { management score after intervention } \\
0.091(95 \% \mathrm{Cl} 0.037 \text { to } 0.144)\end{array}$ \\
\hline Katon $2010^{31}$ & $\begin{array}{l}\text { Depression and } \\
\text { diabetes or coronary } \\
\text { heart disease, or } \\
\text { both }(n=214)\end{array}$ & $\begin{array}{l}\text { Intervention } 12 \\
\text { months, follow-up } \\
\text { at } 12 \text { months }\end{array}$ & $\begin{array}{l}\text { Organisational: TEAMcare } \\
\text { nurses, structured visits, patient } \\
\text { care plans and treatment targets, } \\
\text { weekly team meetings, and use } \\
\text { of electronic registry to track } \\
\text { patient progress. Professional: } \\
\text { education of nurse managers. } \\
\text { Patient: support for self care } \\
\text { (behavioural activation theory) }\end{array}$ & $\begin{array}{l}\text { Primary outcomes: depression } \\
\text { scores (SCL-20); diabetes } \\
\text { (glycated haemoglobin); systolic } \\
\text { blood pressure; and low density } \\
\text { lipoprotein cholesterol. } \\
\text { Secondary outcomes: increases } \\
\text { in drug adjustments, quality of } \\
\text { life, and satisfaction with care }\end{array}$ & $\begin{array}{l}\text { Adjusted between group difference } \\
(95 \% \mathrm{Cl}) \text { : depression scores SCL-20) } \\
-0.41(-0.56 \text { to }-0.26) ; \text { glycated } \\
\text { haemoglobin }-0.56 \%(-0.85 \% \text { to } \\
-0.27 \%) ; \text { systolic blood pressure }(\mathrm{mm} \\
\mathrm{Hg})-3.4(-6.9 \text { to } 0.1) ; \text { low density } \\
\text { lipoprotein cholesterol (mg/dL) }-9.1 \\
(-17.5 \text { to }-0.8)\end{array}$ \\
\hline Krska $2001^{27}$ & $\begin{array}{l}\text { Aged }>65 \text {, at least } \\
\text { two conditions } \\
(n=332)\end{array}$ & $\begin{array}{l}\text { Intervention three } \\
\text { months, follow-up } \\
\text { three months after } \\
\text { drug review }\end{array}$ & $\begin{array}{l}\text { Senior care connections: } \\
\text { structured visit with } \\
\text { pharmaceutical patient care plan } \\
\text { created by pharmacist and } \\
\text { implemented by practice team }\end{array}$ & $\begin{array}{l}\text { Primary outcome: } \\
\text { pharmaceutical care issues. } \\
\text { Secondary outcomes: medicine } \\
\text { costs, quality of life, and health } \\
\text { service use }\end{array}$ & $\begin{array}{l}\text { Pharmaceutical care issues (\%) } \\
\text { resolved after intervention: } 82.7 \% v \\
41.2 \%, \mathrm{P}<0.001\end{array}$ \\
\hline
\end{tabular}


Table 1 (continued)

\begin{tabular}{|c|c|c|c|c|c|}
\hline Study & Study participants & $\begin{array}{l}\text { Duration and } \\
\text { follow-up }\end{array}$ & $\begin{array}{l}\text { Intervention elements; } \\
\text { (theoretical framework, where } \\
\text { specified) }\end{array}$ & Outcomes & $\begin{array}{l}\text { Results (primary outcomes, where } \\
\text { specified): intervention versus } \\
\text { control }\end{array}$ \\
\hline $\begin{array}{l}\text { Sommers } \\
2000^{29}\end{array}$ & $\begin{array}{l}\text { Aged }>65 \text {, at least } \\
\text { two conditions } \\
(n=543)\end{array}$ & $\begin{array}{l}\text { Intervention two } \\
\text { years, follow-up } 12 \\
\text { months after } \\
\text { intervention }\end{array}$ & $\begin{array}{l}\text { Organisational: enhanced } \\
\text { multidisciplinary team including } \\
\text { social worker, home } \\
\text { assessment, and patient care } \\
\text { plans, professional: training of } \\
\text { care coordinators }\end{array}$ & $\begin{array}{l}\text { Health service use including } \\
\text { admissions, office visits, } \\
\text { emergency department visits, } \\
\text { home care visits, and nursing } \\
\text { home visits. Patient reported } \\
\text { health status: social activities } \\
\text { count, quality of life, depression } \\
\text { scores, nutrition checklists, and } \\
\text { drug adherence }\end{array}$ & $\begin{array}{l}\text { Odds ratio admissions/patient/year } 0.63 \\
(95 \% \mathrm{Cl} 0.41 \text { to } 0.96) ; \geq 160 \text { day } \\
\text { readmissions } 0.26(0.08 \text { to } 0.84) \text {. Not } \\
\text { fully reported for seven other outcomes, } \\
\text { non-significant for six. Difference in } \\
\text { adjusted mean scores, social activities } \\
\text { count } 0.50 \text { ( } 95 \% \mathrm{Cl} 0.02 \text { to } 1.00) \text {. } \\
\text { Symptom scale } 0.50 \text { ( }-3.20 \text { to } 0.16) \text {, } \\
\text { SF-36 self rated health } 0.10(-0.27 \text { to } \\
0.02) \text {, not reported for four other } \\
\text { outcomes, non-significant }\end{array}$ \\
\hline
\end{tabular}

Predominantly

patient

oriented:

\begin{tabular}{|c|c|c|c|c|c|}
\hline Eakin $2007^{23}$ & $\begin{array}{l}\text { Multimorbidity } \\
\text { defined as at least } \\
\text { two conditions } \\
\text { ( } \mathrm{n}=175) \text { (data for } \\
\text { multimorbidity group } \\
\text { from authors) }\end{array}$ & $\begin{array}{l}\text { Intervention } 16 \\
\text { weeks, follow-up } \\
\text { six months after } \\
\text { intervention }\end{array}$ & $\begin{array}{l}\text { Patient: self management } \\
\text { support, diet, and exercise } \\
\text { intervention delivered by health } \\
\text { educator; organisational: } \\
\text { structured visits and telephone } \\
\text { contact (chronic care model: } \\
\text { patient self management) }\end{array}$ & $\begin{array}{l}\text { Dietary behaviour, support for } \\
\text { healthy lifestyles, and physical } \\
\text { activity }\end{array}$ & $\begin{array}{l}\text { Adjusted mean (SE): dietary behaviour } \\
\text { (lower score better) } 2.20(0.05) v 2.41 \\
(0.05), \mathrm{P}<0.5 \text {; support for healthy } \\
\text { lifestyle (higher score better) } 2.98(0.06) \\
v 2.68(0.06), \mathrm{P}<0.05 \text {; change minutes } \\
\text { walking/week } 8(22) v-10(27), \mathrm{P}>0.5\end{array}$ \\
\hline$\underset{32}{\text { Gitlin } 2006^{24}}$ & $\begin{array}{l}\text { Aged }>70 \text {, multiple } \\
\text { conditions and } \\
\text { reported difficulties } \\
\text { with activities of } \\
\text { daily living }(n=319)\end{array}$ & $\begin{array}{l}12 \text { months } \\
\text { intervention, } \\
\text { follow-up at } \\
\text { completion of } \\
\text { intervention, four } \\
\text { year mortality } \\
\text { follow-up }\end{array}$ & $\begin{array}{l}\text { Patient (Advancing Better Living } \\
\text { for Elders, ABLE): occupational } \\
\text { therapy and physiotherapy home } \\
\text { based intervention including } \\
\text { balance and muscle } \\
\text { strengthening and fall recovery } \\
\text { techniques, patient: problem } \\
\text { solving techniques (lifespan } \\
\text { theory of control) }\end{array}$ & $\begin{array}{l}\text { Primary outcomes: functional } \\
\text { difficulty (activities of daily } \\
\text { living, activities of daily living, } \\
\text { instrumental activities of daily } \\
\text { living, and mobility), self } \\
\text { efficacy and fear of falling (self } \\
\text { efficacy for falls). Secondary } \\
\text { outcomes: adaptive strategy } \\
\text { use and presence of home } \\
\text { hazards. Four year follow-up: } \\
\text { mortality }\end{array}$ & $\begin{array}{l}\text { Difference in adjusted means at } 12 \\
\text { months: activities of daily living }-0.10 \\
(95 \% \mathrm{Cl}-0.21 \text { to } 0.02) \text {; instrumental } \\
\text { activities of daily living }-0.12(-0.26 \text { to } \\
0.03) \text {; mobility }-0.14(-0.29 \text { to } 0.01) \text {; } \\
\text { overall self efficacy } 0.09 \text { ( }-0.06 \text { to } 0.23) \text {; } \\
\text { fear of falling } 0.56(0.15 \text { to } 0.97) \text {; } \\
\text { mortality at two years } 5.6 \% \text { ( } 9 \text { deaths) } \\
v 13.2 \% \text { ( } 21 \text { deaths), } P=0.02 \text {. Mortality } \\
\text { at four years no significant difference, } \\
\text { intervention increased survivorship by } \\
3.5 \text { years }\end{array}$ \\
\hline $\begin{array}{l}\text { Hochhalter } \\
2010^{25}\end{array}$ & $\begin{array}{l}\text { Aged }>65 \text {, at least } \\
\text { two of seven chronic } \\
\text { conditions }(n=79)\end{array}$ & $\begin{array}{l}\text { Intervention three } \\
\text { months, follow-up } \\
\text { three months after } \\
\text { intervention }\end{array}$ & $\begin{array}{l}\text { Patient engagement intervention } \\
\text { led by "coaches" with focus on } \\
\text { making most of healthcare } \\
\text { (chronic care model: patient self } \\
\text { management) }\end{array}$ & $\begin{array}{l}\text { Primary outcome: patient } \\
\text { activation measure. Secondary } \\
\text { outcomes: total unhealthy days, } \\
\text { self efficacy, and self rated } \\
\text { health }\end{array}$ & $\begin{array}{l}\text { Patient activation measure: reported as } \\
\text { no significant difference between } \\
\text { intervention and control at follow-up }\end{array}$ \\
\hline Lorig $1999^{28}$ & $\begin{array}{l}\text { Aged }>40 \text {, at least } \\
\text { two of heart } \\
\text { disease, lung } \\
\text { disease, arthritis, or } \\
\text { stroke }(n=536) \\
\text { (subgroup of } \\
\text { patients with } \\
\text { comorbidities) }\end{array}$ & $\begin{array}{l}\text { Intervention seven } \\
\text { weeks, follow-up at } \\
\text { six months }\end{array}$ & $\begin{array}{l}\text { Patient (weekly community } \\
\text { based meetings led by trained } \\
\text { volunteer lay leaders focusing } \\
\text { on self management and peer } \\
\text { support) (Bandura's self efficacy } \\
\text { theory) }\end{array}$ & $\begin{array}{l}\text { Health service use: admissions, } \\
\text { emergency department plus } \\
\text { visits to physician. Health } \\
\text { behaviours: four measures. } \\
\text { Health status: eight measures }\end{array}$ & $\begin{array}{l}\text { Adjusted mean difference (SD). Number } \\
\text { of admissions } 0.19(0.73) v 0.33(1.2) \text {, } \\
\mathrm{P}<0.5 \text {; nights in hospital } 1.05(6.3) v 2.1 \\
(6.8), \mathrm{P}<0.5 \text {; number of physician visits } \\
4.96(6.1) v 6.87(7.2), \mathrm{P}>0.5 \text {. } \\
\text { Significance of } 12 \text { measures relating to } \\
\text { health behaviours and health status in } \\
\text { comorbidity subgroup not reported }\end{array}$ \\
\hline
\end{tabular}


Table 2| Intervention elements in included studies

\begin{tabular}{|c|c|}
\hline Intervention element & Studies \\
\hline \multicolumn{2}{|l|}{ Professional } \\
\hline Education or training of care coordinators & Boult $^{22}$, Katon $^{31}$, Sommers $^{29}$ \\
\hline \multicolumn{2}{|l|}{ Financial } \\
\hline \multicolumn{2}{|l|}{ Patient } \\
\hline Self management support and patient education & Eakin $^{23 \star}$, Boult, Katon, Lorig ${ }^{28 *}$, Hochhalter ${ }^{25 *}$ \\
\hline Peer support & Lorig \\
\hline \multicolumn{2}{|l|}{ Organisational } \\
\hline \multicolumn{2}{|l|}{ Provider: } \\
\hline Care coordination or management & Bognor $^{30 *}$, Boult", Katon ${ }^{*}$, Sommers $^{29}$ \\
\hline Enhanced multidisciplinary team (for example, addition of pharmacist or social worker) & $\operatorname{Hogg}^{26 *}$, Katon, Krska ${ }^{27 \star}$, Sommers ${ }^{\star}$ \\
\hline \multicolumn{2}{|l|}{ Patient: } \\
\hline Individual care plans & Bognor, Boult, Hogg, Katon, Krska, Sommers \\
\hline \multicolumn{2}{|l|}{ Structural: } \\
\hline Structured visits & Eakin, Bognor, Boult, Hogg, Katon, Krska \\
\hline Structured telephone contact & Bognor, Eakin, Hochhalter, Hogg \\
\hline
\end{tabular}

\section{Regulatory $\dagger$}

${ }^{*}$ No studies reported on this element. 


\section{Figures}

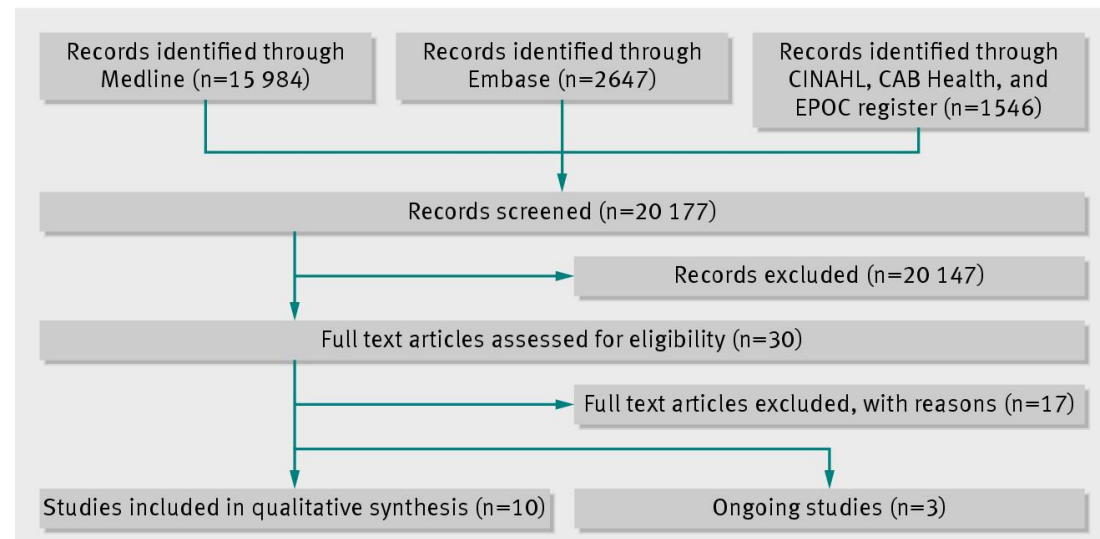

Fig 1 Study flow of papers through review

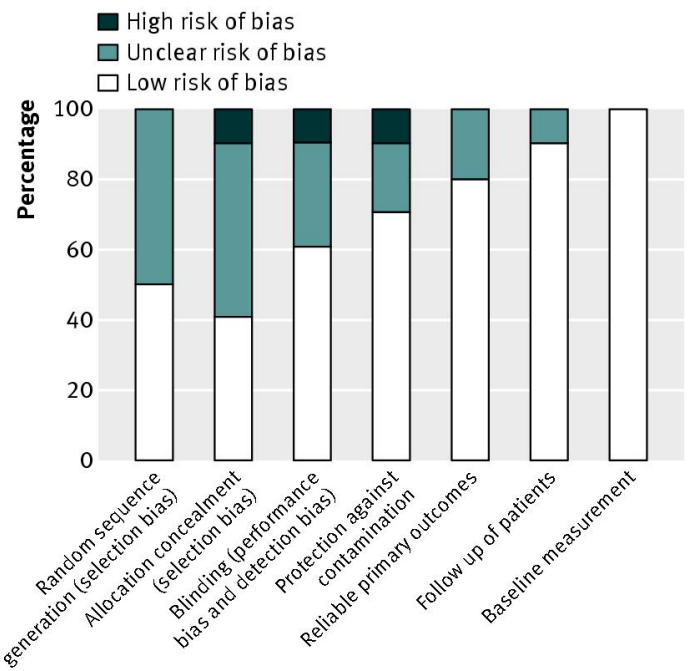

Fig 2 Risk of bias in included studies 